\title{
Treatment of cellulite deformities of the thighs with topical aminophylline gel
}

\author{
J Sheldon Artz MD FACS, Melvyn I Dinner MD FRCS \\ The Center for Plastic Surgery, Inc, Cleveland, Ohio, USA
}

\begin{abstract}
JS Artz, MI Dinner. Treatment of cellulite deformities of the thighs with topical aminophylline gel. Can J Plast Surg 1995;3(4):190-192. Cellulite deformities of the lateral thighs and buttocks are a poorly understood phenomenon, an embarrassment for even the fittest of women, and a frustration for the cosmetic surgeon. Multiple treatments have been attempted for this particular malady, and none have been universally successful. Early reports of the use of topical aminophylline/theophylline gel have shown pleasing improvements in the texture of the skin as early as three weeks after application.
\end{abstract}

Key Words: Cellulite deformities, Thighs, Topical aminophylline gel

Traitement des difformités dues à la cellulite au niveau des cuisses à l'aide d'un gel d'aminophylline topique

RÉSUMÉ: Les difformités liées à la cellulite sur la face latérale des cuisses et au siège sont un phénomène mal compris. Elles incommodent les femmes même les plus en forme et sont un défi de taille pour le spécialiste en chirurgie esthétique. De nombreux traitements ont été mis à l'essai pour vaincre cette maladie particulière. Aucun n'a donné de résultats universellement satisfaisants. Les rapports préliminaires sur l'emploi d'un gel d'aminophylline-théophylline topique font état d'améliorations appréciables sur le plan de la texture de la peau, en trois semaines de traitement à peine.

The early reports on the use of topical aminophylline cream (1) were very interesting because they proposed a possible nonsurgical solution to the fatty deposits on the thigh. Initially these reports were positive for weight reduction; however, being very sceptical, we have undertaken studies to determine whether or not there were apparent changes in the skin texture (cellulite) with the use of topical aminophylline/theophylline cream. Cellulite deformities were defined as topical geographical changes in the smooth appearance of the skin of the thighs and buttocks. These changes are most commonly seen in women over 35 years of age. It is also assumed that cellulite is caused by thickening of the subdermal fat layer causing the fibrous connections from the dermis to the fascia to stretch in certain areas and contract in others, thus producing the cobblestone appearance of the skin.

Theophylline is a xanthene derivative. When theophylline is combined with ethylene diamine in anhydrous alcohol, it forms the compound aminophylline. The exact 
mode of action of this aminophylline/theophylline compound is unsettled but there are several proposed theories. Aminophylline is known to be a smooth muscle relaxant. Aminophylline/theophylline does cause inhibition of the phosphodiesterase with resultant increase in intracellular adenosine monophosphate (AMP) (2). It has been suggested that aminophylline/theophylline inhibits the activity of certain hormones that cause a woman's body to store fat and therefore release intracellular triglycerides. It is thought that xanthene derivatives block the receptors for these fat storage hormones on the fat cell causing the cell to release instead of retain its triglyceride contents. Other proposed mechanisms of action include translocation of intracellular calcium, prostaglandin antagonism, stimulation of catecholamines endogenously, and an inhibition of cyclic guanacine monophosphate metabolism, and possibly an adenosine receptor antagonism.

According to the Physicians' Desk Reference (2), none of these proposed mechanisms has been proven.

We undertook the present study to seek answers to a number of questions concerning the use of aminophylline gel applied topically to cellulite deformities of the lateral thighs and buttocks. Is aminophylline absorbed into the bloodstream after being topically applied? Are there any changes in the lipid profile of the patient applying the topical aminophylline gel, including total cholesterol, triglycerides, high density (HDL) and low density (LDL) lipoprotein cholesterol. Are there any changes in the actual measurements of the circumference of the waist, thighs and hips once the aminophylline cream has been used? Is there any visual evidence of a change in the so-called cellulite characteristics of the thigh? Can these changes be substantiated by ultrasonic examination of the thigh?

\section{METHOD}

The study comprised 12 volunteers and included pretreatment photographs, aminophylline serum levels, lipid profiles (triglycerides, HDL, LDL and total cholesterol), blood glucose levels, ultrasounds of the skin in the area of the lateral thighs, and measurements of the thighs, waist, and hips. The aminophylline/theophylline gel (Opticell-U-Lite ${ }^{\mathrm{TM}}$ Gel; Opticell Skin Care Services, Inc, Cleveland) was then liberally applied $(5 \mathrm{~mL})$ in a $2 \%$ solution to the lateral thighs and buttocks both morning and evening and the study commenced. These patients were evaluated at $1 \mathrm{~h}$, three weeks, six weeks and three months.

The patients did not ingest caffeine on the day of the study, and they also avoided any other medications that have proven to enhance or decrease the serum levels of theophylline. Serum levels were measured initially before the application of the aminophylline/theophylline gel and then repeated $1 \mathrm{~h}$ after the application. Repeat studies were then performed three weeks, six weeks and three months after the beginning of the study. Ultrasound was performed pretreatment and at a three-month time frame.

\section{RESULTS}

The aminophylline/theophylline levels before therapy ranged from $0 \mu \mathrm{g} / \mathrm{mL}$ to $0.3 \mu \mathrm{g} / \mathrm{mL}$. Total cholesterol ranged from 129 to $220 \mathrm{mg} / \mathrm{dL}$, triglycerides from 69 to $113 \mathrm{mg} / \mathrm{dL}$, HDL cholesterol from 33 to $79 \mathrm{mg} / \mathrm{dL}$ and LDL from 67 to $128 \mathrm{mg} / \mathrm{dL}$. These were all within accepted normal levels for the average age of our patients which varied from 35 to 48 years old. These lipid levels did not show any significant changes 
after three weeks, six weeks or three month. After $1 \mathrm{~h}$ following the application of the aminophylline/theophylline gel, the serum blood levels of aminophylline ranged from 0.4 $\mu \mathrm{g} / \mathrm{mL}$ to a high of $1.0 \mu \mathrm{g} / \mathrm{mL}$. After six weeks, the theophylline levels ranged from 0.4 $\mu \mathrm{g} / \mathrm{mL}$ to $1.1 \mu \mathrm{g} / \mathrm{mL}$, and after three months they ranged from $0.0 \mu \mathrm{g} / \mathrm{mL}$ to $0.5 \mu \mathrm{g} / \mathrm{mL}$ (Table 1). The patients in the study avoided any medications known to interfere with theophylline blood levels (eg, allopurinol, cimetidine, ciprofloxacin, erythromycin, lithium, oral contraceptives, phenytoin and propranolol) but did not refrain from drinking coffee after the first hour of the study.

TABLE 1: Aminophylline blood levels in patients pretreatment and at $1 \mathrm{~h}$, six weeks and three months following treatment

\begin{tabular}{|l|l|l|l|l|l|}
\hline \multirow{2}{*}{$\begin{array}{l}\text { Patient } \\
\text { number }\end{array}$} & \multicolumn{3}{|l|}{ Aminophylline blood levels $(\mu \mathrm{g} / \mathrm{mL})$} \\
\cline { 2 - 5 } & Pretreatment & $\mathbf{1}$ h & 6 weeks & $\mathbf{3}$ months \\
\hline 1 & 0.1 & 0.1 & 1.1 & 0.8 \\
\hline 2 & 0.1 & 0.2 & 1.0 & 1.2 \\
\hline 3 & 0.0 & 0.1 & 0.5 & 0.7 \\
\hline 4 & 0.2 & 0.2 & 0.7 & 1.1 \\
\hline 5 & 0.0 & 0.0 & 0.5 & 0.6 \\
\hline 6 & 0.2 & 0.3 & 0.7 & 1.1 \\
\hline 7 & 0.1 & 0.0 & 0.4 & 0.4 \\
\hline 8 & 0.3 & 0.5 & 0.7 & 0.3 \\
\hline 9 & 0.2 & 0.2 & 0.8 & 0.8 \\
\hline 10 & 0.0 & 0.0 & 0.6 & 0.8 \\
\hline 11 & 0.1 & 0.0 & 0.4 & 0.3 \\
\hline 12 & 0.1 & 0.1 & 0.3 & 0.2 \\
\hline
\end{tabular}

Any measurement under $2 \mu \mathrm{g} / \mathrm{mL}$ is difficult to measure and is subject to the sensitivity of the machine

Waist and hips measurements did not change over the three month study period. The measurements around the thighs were decreased an average of $0.5 \mathrm{~cm}$, but with no weight reduction.

Photographic analysis of the patients showed an improved appearance in all of the patients, some more dramatic than others (Figures 1,2). 


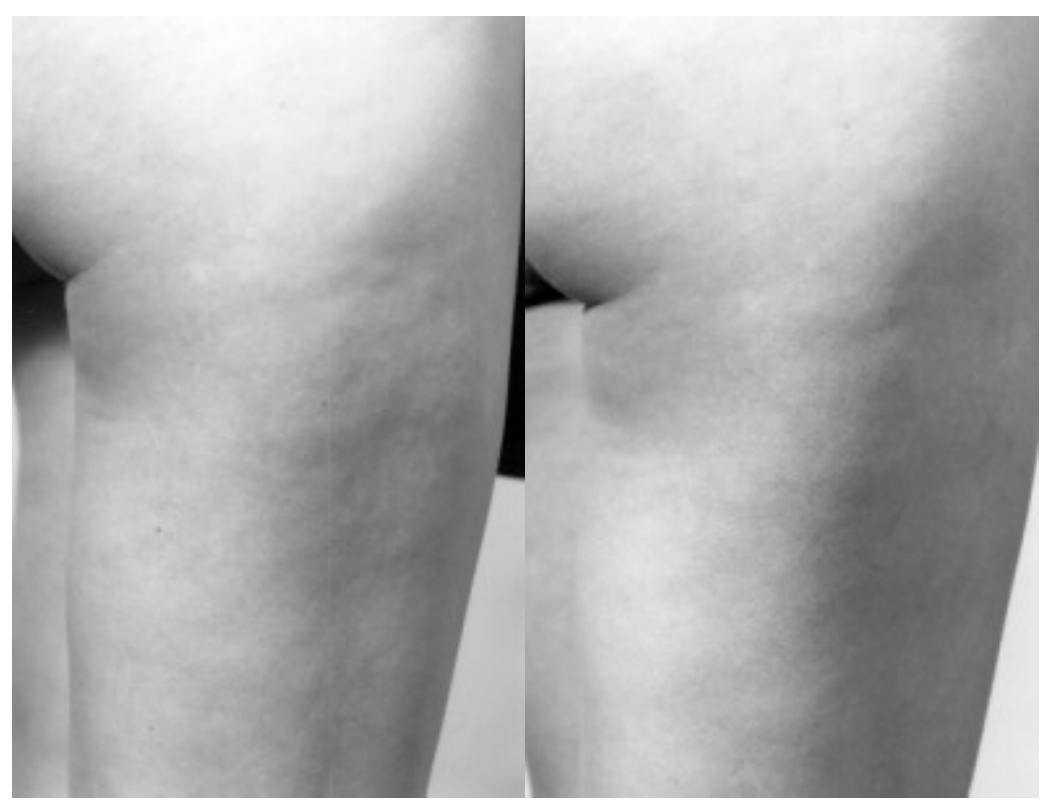

Figure 1) Pretreatment (left) and six weeks post-treatment (right) with aminophylline gel

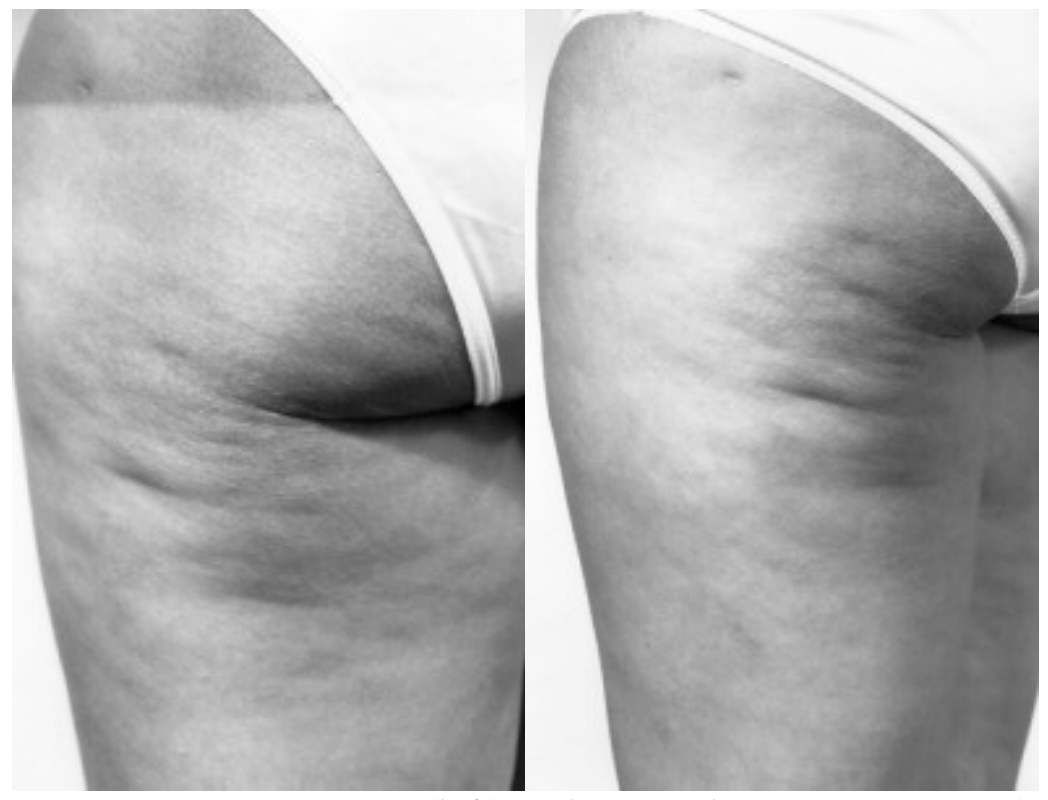

Figure 2) Pretreatment (left) and six weeks post-treatment (right) with aminophylline gel

Interestingly, in eight of 12 patients, ultrasound of the lateral thigh done initially and at the three month interval showed definite changes with thinning of the subcutaneous layer after the application of the aminophylline gel. The demarcation between the cutaneous and dermal layer was much easier to see in the post treatment study (Figures 3,4). The results of the ultrasound corresponded with the visual evidence of changes in the cellulite of these patients. 

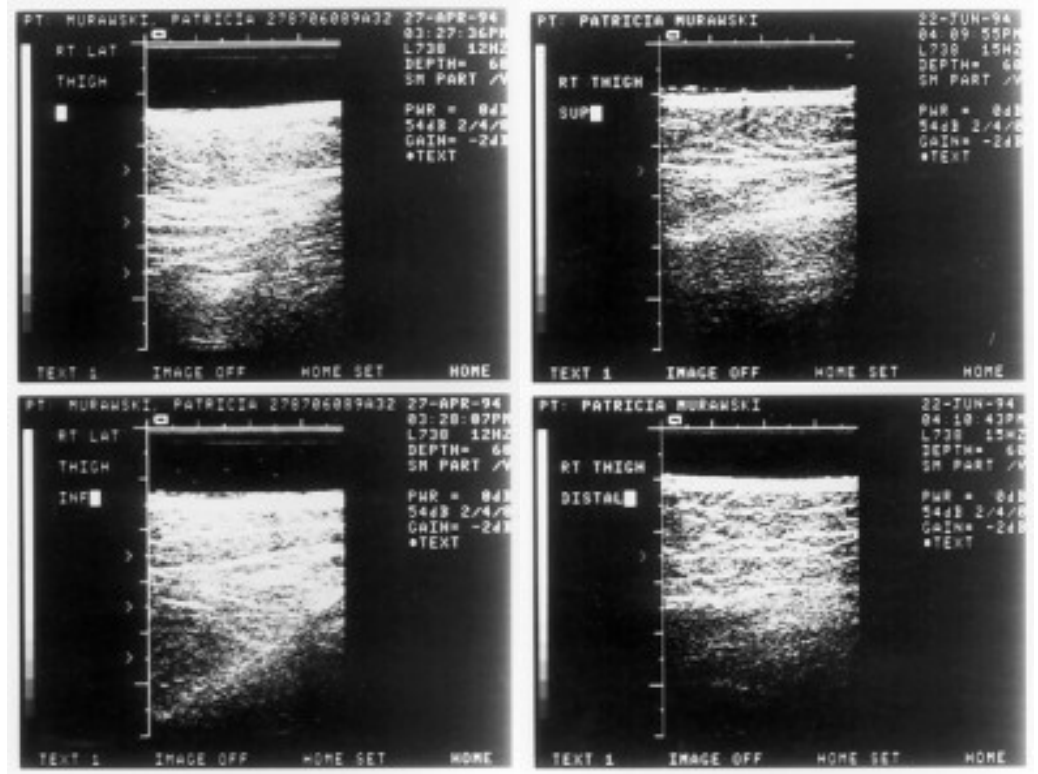

Figure 3) Ultrasound of lateral thigh showing pretreatment (left) and three months posttreatment (right) with aminophylline gel
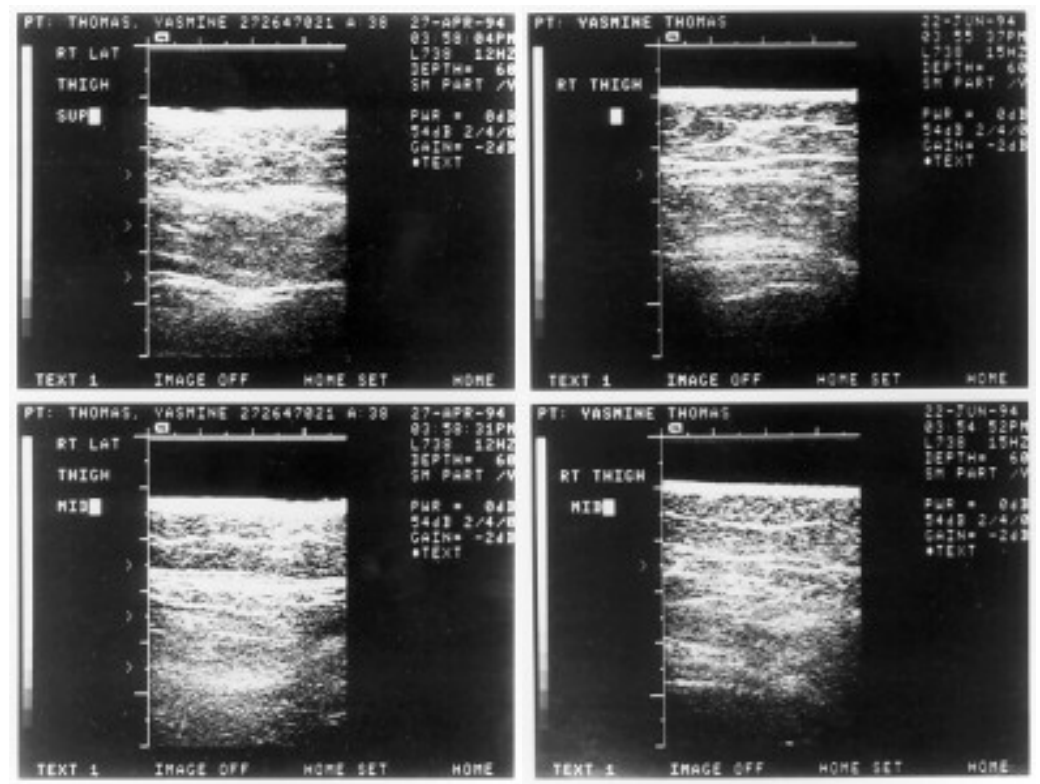

Figure 4) Ultrasound of lateral thigh showing pretreatment (left) and three months posttreatment (right) with aminophylline gel

\section{CONCLUSIONS}

Aminophylline/theophylline topically applied produced pleasing improved visual results in the change in cellulite in the lateral thighs of all 12 patients in this study. Ultrasound evidence of improvement in eight of the 12 patients, with decreased thickness of the subcutaneous layer, was also seen. The measurement of the waist and thighs did not change at all, nor did the patient's weight over the three month study period.

Measurements around the thigh in eight of the 12 patients were slightly improved. There 
was minimal absorption of aminophylline into the bloodstream. Several patients said that they felt a tingling or other subjective symptoms when applying the cream, similar to the feelings that they experienced when they drank their first cup of coffee in the morning. This could not be substantiated by direct measurement.

We conclude that a $2 \%$ aminophylline gel, topically applied, is a safe, effective, and noninvasive way to treat cellulite deformities of the thighs. However, caution should be used when combining aminophylline with drugs that are known to potentiate its effects. We are now in the process of preparing a double-blind study on its use.

\section{REFERENCES}

1. Hamilton EC, Greenway FL, Bray GA. Regional fat loss from the thigh in women using topical $2 \%$ aminophylline. J Obesity

2. Physicians' Desk Reference. Montvale, New Jersey: Medical Economics Data

Production Co, 1994. 